Wright State University

CORE Scholar

Physics Faculty Publications

Physics

$5-1-2002$

\title{
Deep Hole Traps in N-GaN Films Grown by Hydride Vapor Phase Epitaxy
}

A. Y. Polyakov

N. B. Smirnov

A. V. Govorkov

Z-Q. Fang

David C. Look

Wright State University - Main Campus, david.look@wright.edu

See next page for additional authors

Follow this and additional works at: https://corescholar.libraries.wright.edu/physics

Part of the Physics Commons

\section{Repository Citation}

Polyakov, A. Y., Smirnov, N. B., Govorkov, A. V., Fang, Z., Look, D. C., Molnar, R. J., \& Osinsky, A. V. (2002). Deep Hole Traps in N-GaN Films Grown by Hydride Vapor Phase Epitaxy. Journal of Applied Physics, 91 (10), 6580-6584.

https://corescholar.libraries.wright.edu/physics/152

This Article is brought to you for free and open access by the Physics at CORE Scholar. It has been accepted for inclusion in Physics Faculty Publications by an authorized administrator of CORE Scholar. For more information, please contact library-corescholar@wright.edu. 


\section{Authors}

A. Y. Polyakov, N. B. Smirnov, A. V. Govorkov, Z-Q. Fang, David C. Look, Richard J. Molnar, and A. V. Osinsky 


\title{
Deep hole traps in $\boldsymbol{n}$-GaN films grown by hydride vapor phase epitaxy
}

\author{
A. Y. Polyakov, N. B. Smirnov, and A. V. Govorkov \\ Institute of Rare Metals, Moscow, 109017, B. Tolmachevsky, 5, Russia
}

Z.-Q. Fang ${ }^{\text {a) }}$ and D. C. Look

Semiconductor Research Center, Wright State University, Dayton, Ohio 45435

and Materials \& Manufacturing Directorate, Air Force Research Laboratory, Wright-Patterson Air Force Base, Ohio 45433

R. J. Molnar

Lincoln Laboratory, Massachusetts Institute of Technology, Lexington, Massachusetts 02173

\author{
A. V. Osinsky \\ Corning Applied Technologies, 14 Gill Street, Woburn, Massachusetts 01801
}

(Received 29 January 2002; accepted for publication 19 February 2002)

Concentrations of deep hole traps were measured in a set of hydride vapor phase epitaxy grown samples with thicknesses varying from 2.6 to $68 \mu \mathrm{m}$. Results were obtained from low temperature capacitance-voltage measurements before and after illumination and from deep level transient spectroscopy measurements with optical injection (ODLTS). The former revealed the presence of high densities $\left(\sim 10^{15}\right.$ to $\left.10^{16} \mathrm{~cm}^{-3}\right)$ of hole traps whose concentration decreased with sample thickness in a manner similar to that found for the dislocation density. Capacitance versus temperature measurements in the dark and after illumination suggested that these traps form a band of states rather than a single level in the GaN band gap. It is suggested that such states could be associated with dislocations. The main hole traps observed by ODLTS were deep hole traps, of energy near $E_{v}+0.9 \mathrm{eV}$. Their density was also observed to substantially decrease with sample thickness. (C) 2002 American Institute of Physics. [DOI: 10.1063/1.1468909]

\section{INTRODUCTION}

Hydride vapor phase epitaxy (HVPE) is capable of producing thick $\mathrm{GaN}$ layers with dislocation density $\left(N_{\mathrm{dis}}\right)$ greatly reduced compared to that produced by other growth techniques such as molecular beam epitaxy (MBE) or metalorganic chemical vapor deposition (MOCVD). ${ }^{1,2}$ However, $N_{\text {dis }}$ varies strongly along the cross section of HVPE films, with the region adjacent to the sapphire substrate having the highest values of $N_{\text {dis }}$, on the order of $10^{10} \mathrm{~cm}^{-2}$, while that near the surface of 50-100- $\mu$ m-thick films can be as low as $10^{7}$ to $10^{8} \mathrm{~cm}^{-2}{ }^{3}$ The electrical properties of HVPE films were studied in detail in several papers ${ }^{4,5}$ and these studies revealed the presence of a very highly conducting layer near the $\mathrm{GaN} / \mathrm{Al}_{2} \mathrm{O}_{3}$ interface. At the same time differential Hall effect measurements demonstrated a very marked improvement of the electron mobility and a very substantial decrease of the electron concentration with layer thickness, demonstrating a cross-sectional profile much like that of $N_{\text {dis }} \cdot{ }^{3-5}$ Moreover, other studies showed that diffusion lengths also greatly increased with thickness (e.g., from $0.25 \mu \mathrm{m}$ for a thickness of $5 \mu \mathrm{m}$, to $0.63 \mu \mathrm{m}$ for a thickness of $33 \mu \mathrm{m}) .{ }^{6} \mathrm{~A}$ simple model developed in Ref. 7 and predicting that the diffusion lengths in mosaic GaN films are limited by the characteristic dimensions of the domains comprising the film, separated by low angle dislocation boundaries, was invoked to explain the observed behavior. ${ }^{6}$ Electron traps in

\footnotetext{
a)Electronic mail: zhaoqiang.fang@wright.edu
}

the upper half of the band gap of $n$-GaN were studied in detail using the deep level transient spectroscopy (DLTS) technique. ${ }^{3,5,8}$ While the traps in the upper half of the band gap were reasonably well mapped and their behavior somewhat understood, very little is known about the traps in the lower half of the band gap, mainly because such traps are not readily amenable to conventional DLTS measurements on Schottky diodes. In an earlier paper, ${ }^{8}$ we reported on preliminary studies of the hole trap spectra in HVPE and MOCVD films using a variant of the DLTS technique which involved optical injection pulses. ${ }^{9}$ We showed that the dominant centers detected by this technique were hole traps with a level near $E_{v}+0.9 \mathrm{eV}$. We also showed that low-temperature capacitance versus voltage $(C-V)$ measurements and capacitance versus temperature $(C-T)$ measurements suggested the presence of a band of states with aggregate density on the order of $10^{16} \mathrm{~cm}^{-3}$, in the lower half of the band gap of $n$-GaN. In the present article we applied these techniques to a set of HVPE samples with thicknesses ranging from 2.6 to $68 \mu \mathrm{m}$ and with dislocation densities near the surface ranging from $2 \times 10^{9}$ to $10^{8} \mathrm{~cm}^{-2}$.

\section{EXPERIMENT}

The HVPE samples used in this article were cut from the same $\mathrm{HVPE} / \mathrm{Al}_{2} \mathrm{O}_{3}$ wafers for which previously detailed transmission electron microscope (TEM), differential Hall effect, DLTS, and electron beam induced current (EBIC) studies had been reported. ${ }^{3,4,6}$ The growth details can be found in the earlier references. Five samples with nominal 


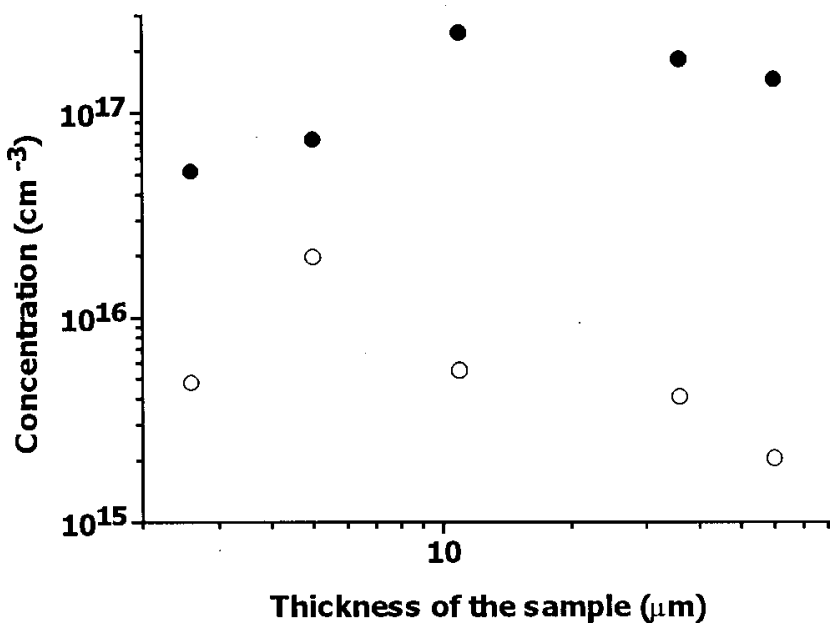

FIG. 1. The thickness dependence of the electron concentration (closed circles) and the density of deep hole traps from $C-V$ results (open circles) in HVPE $n$-GaN samples.

thicknesses of $2.6,5,11,36$, and $68 \mu \mathrm{m}$, respectively, were studied. Au Schottky diodes on the samples were prepared by vacuum deposition through a shadow mask as discussed in Ref. 10. The diodes were $0.75 \times 0.75 \mathrm{~mm}^{2}$ rectangles while the ohmic contacts were In stripes at the sides of the samples. Because of the good electrical conductivity of the samples the series resistance was not a concern up to measurement frequencies higher than $1 \mathrm{MHz}$.

Capacitance-voltage $(C-V)$ measurements were performed at temperatures in the range $85-400 \mathrm{~K}$ for frequencies in the range of $100 \mathrm{~Hz}-10 \mathrm{MHz}$ using an HP4192A impedance analyzer and a gas-flow cryostat. These measurements were carried out either in the dark or during and after illuminating the sample with a deuterium UV lamp with or without selective filters. We also used subband-gap illumination with an array of $\mathrm{GaAs}(\mathrm{Si})$ light emitting diodes (LEDs). The same setup was used for capacitance versus temperature $(C-T)$ measurements at various frequencies.

DLTS spectra with optical injection (hereafter called ODLTS spectra for brevity) were taken in the 85-400 K temperature range using the gas-flow cryostat, an HP4280B $C-V / C-T$ analyzer, and an external pulse generator HP8112A for actuating the deuterium lamp source, equipped with mechanical shutter. At each temperature point the whole relaxation curve was measured and stored which allowed plotting of the ODLTS spectra with any selected $t_{1}$ and $t_{2}$ time window settings. Typically the measurements were taken with $0.5 \mathrm{~K}$ steps in temperature.

\section{RESULTS AND DISCUSSION}

Consider first the results of the $C-V$ and $C-T$ measurements. Apparent electron concentrations deduced from $C-V$ measurements had values close to $10^{17} \mathrm{~cm}^{-3}$ and were slightly varying with thickness, as shown in Fig. 1 (closed circles). The temperature and frequency dependencies of the capacitance and of the measured concentration were very slight.

The most interesting results were obtained from $C-V$ measurements in the dark and after illumination at $85 \mathrm{~K}$.

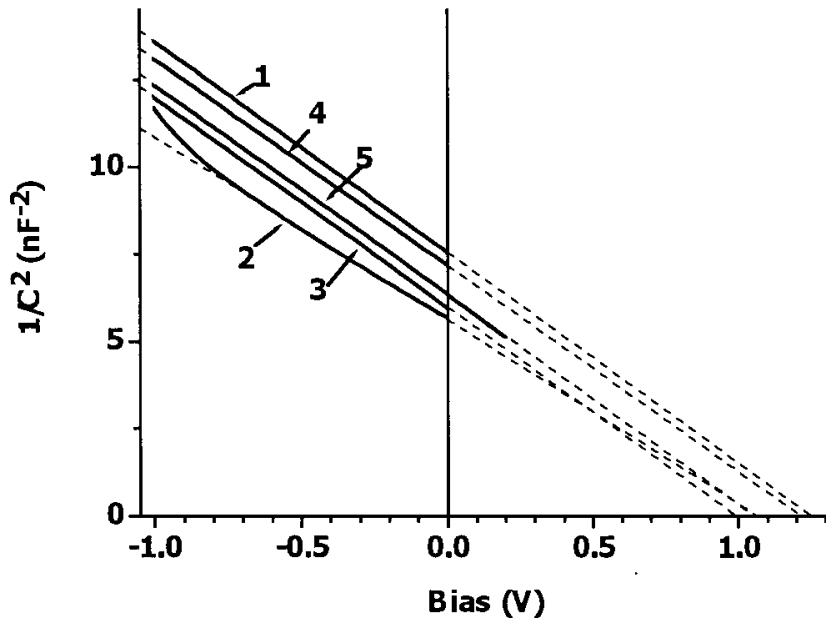

FIG. 2. $1 / C^{2}$ vs voltage plots for the $5 \mu \mathrm{m}$ sample measured at $85 \mathrm{~K}$ in the dark (curve 1); at $85 \mathrm{~K}$ under UV illumination (curve 2); at $85 \mathrm{~K}$ after UV illumination and after waiting for $10 \mathrm{~min}$ (curve 3); after UV illumination, waiting for $10 \mathrm{~min}$, and application of a forward bias of $1 \mathrm{~V}$ for $2 \mathrm{~min}$ (curve 4); also shown is the plot for the $400 \mathrm{~K}$ measurements (curve 5); the measurement frequency is $100 \mathrm{kHz}$.

Figure 2 presents a set of $1 / C^{2}$ versus voltage $V$ plots obtained at $100 \mathrm{kHz}$ on the 5 - $\mu \mathrm{m}$-thick sample. The measurements were performed at $85 \mathrm{~K}$ in the dark (curve 1), at $85 \mathrm{~K}$ under deuterium lamp illumination (curve 2), at $85 \mathrm{~K}$ after UV illumination and 10 min wait in the dark (curve 3), and the same after additional application of a forward bias of $1 \mathrm{~V}$ for 2 min (curve 4). We also show for comparison a $C-V$ plot taken at $400 \mathrm{~K}$ (curve 5). The most obvious feature of the plots shown in Fig. 2 is a very considerable decrease of the intercept voltage at $85 \mathrm{~K}$ after illumination ("persistent" value $V_{\mathrm{bi}}^{P}$ ) compared to the dark value $V_{\mathrm{bi}}$. This change of the built-in voltage only occurred for illumination with above-band-gap light, producing holes. Application of the forward bias of $1 \mathrm{~V}$, as can be seen from Fig. 2, returned the built-in voltage to practically its dark value. This behavior is similar to that already described for a set of MOCVD and HVPE grown samples in Ref. 8. It is explained by the capture of holes by deep acceptor states near the surface. These acceptors are located below the Fermi level and are normally fully occupied by electrons. Capture of holes creates an additional positive space charge near the surface in the space charge region and results in an increase of the measured capacitance and a decrease of the apparent built-in voltage of the diode measured from the intercept value in the $1 / C^{2}(V)$ plot. ${ }^{11}$ Because there are very few electrons in the space charge region near the surface, this excessive positive space charge can only be removed by thermal emission of the holes trapped on the deep acceptors, which requires a very long time at low temperatures. Application of a forward bias supplies the electrons necessary for recombination and thus restores the initial value of the built-in voltage.

This quasi-persistent photocapacitance should be distinguished from the real persistent changes in capacitance owing to the existence of certain donor centers with sufficiently high barrier for capture of electrons. As discussed in Ref. 8 the latter manifest themselves by a persistent increase in the 
TABLE I. The summary of $C-V$ measurement results at $85 \mathrm{~K}$ for various HVPE samples.

\begin{tabular}{llllr}
\hline \hline Sample No. & $V_{\mathrm{bi}}, V$ & $V_{\mathrm{bi}}^{\mathrm{PPC}}, V$ & $w_{0}, \mu \mathrm{m}$ & $N_{t}, \mathrm{~cm}^{-3}$ \\
\hline $1232,2.6 \mu \mathrm{m}$ & 1.232 & 1.141 & 0.153 & $4.3 \times 10^{15}$ \\
$1106,5 \mu \mathrm{m}$ & 1.287 & 1.03 & 0.12 & $2 \times 10^{16}$ \\
$735,11 \mu \mathrm{m}$ & 1.116 & 1.093 & 0.068 & $5.2 \times 10^{15}$ \\
$706,36 \mu \mathrm{m}$ & 1.029 & 1.007 & 0.077 & $4.1 \times 10^{15}$ \\
$266,68 \mu \mathrm{m}$ & 1.14 & 1.115 & 0.08 & $2.1 \times 10^{15}$ \\
\hline \hline
\end{tabular}

density of electrons deduced from $C-V$ characteristics measured after illumination but have very little effect on the built-in voltage of the diode. Comparison of curves 1 and 3 in Fig. 2 indeed shows that the electron concentration after illumination at $85 \mathrm{~K}$ is higher by $4 \times 10^{14} \mathrm{~cm}^{-3}$ than the dark value and this change in concentration is not affected by the application of the forward bias of $1 \mathrm{~V}$ (curve 4) recharging the deep acceptor traps and returning the built-in voltage to its preillumination value. The magnitude of this true persistent photocapacitance effect differed for different samples of the set studied in this article and detailed results of these experiments will be published elsewhere. What is important for us here is that the changes in capacitance caused by these donor centers with a barrier for capture of electrons were always very considerably lower than the changes caused by charging the deep acceptors discussed above.

The relation between the difference in the intercept values in the dark and after illumination at low temperature $\Delta V_{\mathrm{bi}}$ and the density of deep acceptors charged with holes $N_{\text {deep }}$ was developed in Ref. 11:

$$
\Delta V_{\mathrm{bi}}=q \cdot N_{\text {deep }} \cdot w_{0}^{2} /\left(2 \varepsilon \varepsilon_{0}\right),
$$

where $w_{0}$ is the space charge region (SCR) width under illumination (i.e., it is assumed that this is the thickness down to which the deep traps are recharged), $q$ is the electron charge, $\varepsilon_{0}$ is the permittivity of vacuum, and $\varepsilon$ is the relative permittivity. The illumination in the above measurements was performed at zero bias; therefore we are interested in $w_{0}$ at zero bias which can be obtained, e.g., from the $1 / C^{2}(V)$ plot in Fig. 2 taken under illumination.

Table I presents the values of $V_{\mathrm{bi}}, V_{\mathrm{bi}}^{P}$, and $w_{0}$ derived from $85 \mathrm{~K} C-V$ measurements in the dark $\left(V_{\mathrm{bi}}\right)$, with UV illumination ( $w_{0}$ corresponding to $\left.V=0\right)$ and after illumination $\left(V_{\mathrm{bi}}^{P}\right)$ for the present set of HVPE samples as discussed above. The last column of the table gives the densities of the deep hole traps $N_{\text {deep }}$ determined from these measurements using Eq. (1). These values are plotted against the samples thickness in Fig. 1 (open circles). It can be seen that, save for the $2.6 \mu \mathrm{m}$ sample, the $N_{\text {deep }}$ values show the general trend of decrease with thickness. The $2.6 \mu \mathrm{m}$ sample stands apart in that the $N_{\text {deep }}$ in this sample is lower than in the thicker 5 $\mu \mathrm{m}$ sample. The $2.6 \mu \mathrm{m}$ sample was grown with a lower growth rate compared to the rest of the set. Although the density of threading dislocations near the surface measured by TEM was not seriously affected by this change in growth procedure (the dislocation density was close to 2 $\times 10^{9} \mathrm{~cm}^{-2}$ ) this sample showed much better electrical properties than that expected for such thickness. For ex-
TABLE II. Electrical properties of various HVPE samples.

\begin{tabular}{lcccc}
\hline \hline $\begin{array}{c}\text { Sample } \\
\text { No. }\end{array}$ & $\begin{array}{c}n(300 \mathrm{~K}), 10^{17} \\
\mathrm{~cm}^{-3}\end{array}$ & $\begin{array}{c}\mu(300 \mathrm{~K}), \\
\mathrm{cm}^{2} / \mathrm{V} \mathrm{s}\end{array}$ & $\begin{array}{c}\mu \text { (peak), } \\
\mathrm{cm}^{2} / \mathrm{V} \mathrm{s}\end{array}$ & $\begin{array}{c}n_{s}(13 \mathrm{~K}), 10^{14} \\
\mathrm{~cm}^{-2}\end{array}$ \\
\hline $1232,2.6 \mu \mathrm{m}$ & 4 & 252 & 597 & 3 \\
$1106,5 \mu \mathrm{m}$ & 13.6 & 189 & 502 & 18.6 \\
$735,11 \mu \mathrm{m}$ & 4.1 & 427 & 889 & 12.4 \\
$706,36 \mu \mathrm{m}$ & 2.15 & 563 & 1121 & 10 \\
$266,68 \mu \mathrm{m}$ & 1.1 & 737 & 1538 & 5.95 \\
\hline \hline
\end{tabular}

ample, in Table II we present a summary of electrical measurements on the present set of samples. The table shows the apparent electron concentration $n(300 \mathrm{~K})$ and mobility $\mu(300 \mathrm{~K})$, the peak mobility value as a function of temperature $\mu$ (peak), and the value of the sheet electron concentration at $13 \mathrm{~K} n_{s}(13 \mathrm{~K})$. As discussed in some detail in Refs. 4, 5, and 12 the apparent concentrations and mobilities in HVPE films are strongly influenced by parallel conduction in the heavily $n$-type defective layer near the interface. The thinner the sample, the higher the impact of the defect layer on the measured concentration and mobility. At the same time, as argued in Ref. 12, the sheet electron concentration at very low temperatures is a good measure of the concentration in the defect layer because at these low temperatures the carriers in the bulk of the film are mostly frozen out. Hence, for a given defect layer, one would expect to see the apparent concentration and mobility decrease and increase, respectively, with thickness, and the low temperature sheet concentration to remain approximately constant. This is more or less the case for our samples with thicknesses of $5 \mu \mathrm{m}$ and higher but the $2.6 \mu \mathrm{m}$ sample shows the apparent concentration and mobility considerably better than those of the $5 \mu \mathrm{m}$ sample and almost as good as those of the $11 \mu \mathrm{m}$ sample. At the same time it is characterized by the lowest $13-\mathrm{K}$ sheet electron concentration among all of the samples (see Table II).

The $C-T$ curves of the illuminated samples show a very broad stage where the capacitance remains considerably higher than that of the $C-T$ curves measured in the dark (Fig. 3). If the acceptors we are dealing with had a single

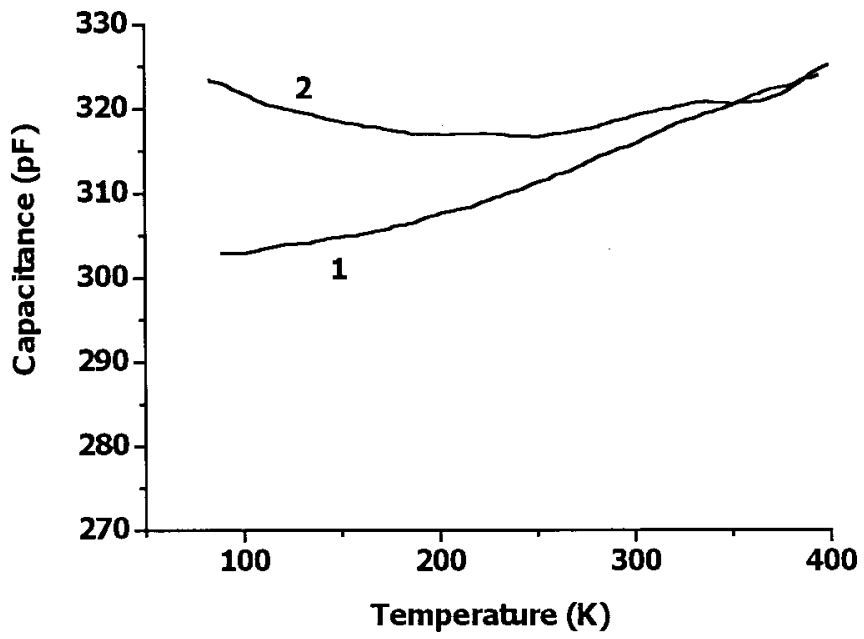

FIG. 3. The dependence of zero bias capacitance at $1 \mathrm{kHz}$ on temperature for cooling in the dark (curve 1) and heating up after deuterium UV lamp illumination at $85 \mathrm{~K}$ (curve 2) for the $5 \mu \mathrm{m}$ sample. 


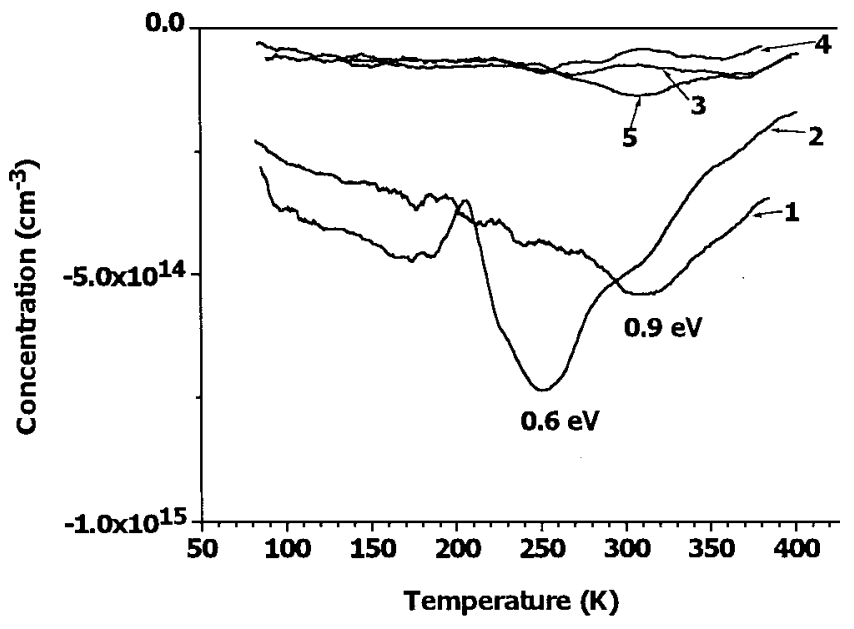

FIG. 4. ODLTS spectra taken on the $2.6 \mu \mathrm{m}$ sample (curve 1), the $5 \mu \mathrm{m}$ sample (curve 2), the $11 \mu \mathrm{m}$ sample (curve 3), the $36 \mu \mathrm{m}$ sample (curve 4), and the $68 \mu \mathrm{m}$ sample (curve 5); the reverse bias is $-0.5 \mathrm{~V}$, the deuterium UV lamp illumination pulse, $5 \mathrm{~s}$ long, and the time windows, $t_{1} / t_{2}$ $=600 \mathrm{~ms} / 6000 \mathrm{~ms}$.

discreet level in the band gap one would expect to see a sharp, well defined recovery stage. The broad feature we observe in Fig. 3 could rather belong to a set of several levels or a band of states, as one would expect for dislocations. Similar observations were previously reported in Ref. 8 for HVPE and MOCVD grown $n$-GaN films with high dislocation densities.

The results of ODLTS measurements on the present set of HVPE samples are shown in Fig. 4. It can be seen that in the thin 2.6 and $5 \mu \mathrm{m}$, and the thick $68 \mu \mathrm{m}$ samples, a deep hole trap (i.e., one for which the capacitance decreases with time during the capacitance transient ${ }^{9}$ ) with a level near $E_{v}$ $+0.9 \mathrm{eV}$ is detected (corresponding to curves 1, 2, and 5 in Fig. 4). Its concentration is rather high in the thin samples (about $6 \times 10^{14} \mathrm{~cm}^{-3}$ for the $2.6 \mu \mathrm{m}$ sample, about 7.5 $\times 10^{14} \mathrm{~cm}^{-3}$ for the $5 \mu \mathrm{m}$ sample) and drops to about 1.5 $\times 10^{14} \mathrm{~cm}^{-3}$ in the $68 \mu \mathrm{m}$ sample. In addition to that, both thinner samples show a very broad band-like feature at low temperatures and the magnitude of the related signal is very considerably lower in the thick, $68 \mu \mathrm{m}$ sample. In the $5 \mu \mathrm{m}$ sample, we also observe a rather broad hole-trap-like feature with apparent activation energy of $0.6 \mathrm{eV}$, absent in the other samples. Interestingly, the ODLTS spectra of the two samples with intermediate thicknesses of 11 and $36 \mu \mathrm{m}$ show no appreciable concentrations of the $E_{v}+0.9 \mathrm{eV}$ hole traps. Instead, some deeper traps, for which the activation energy was not measured, were found at low concentration in the high-temperature portions of the spectra (see curves 3 and 4 in Fig. 4). In the DLTS studies of the electron traps in the present set of samples, the samples with intermediate thicknesses also demonstrated nonmonotonic behavior in terms of the types and concentrations of the deep traps ${ }^{3}$ which could be a manifestation of a changing interaction between the point defects and dislocations as the dislocation density goes down. The $E_{v}+0.9 \mathrm{eV}$ hole traps are often found to be present in $n$-GaN films and their concentration can vary over a wide range from below detection limit up to about $10^{15} \mathrm{~cm}^{-3}$ in some MOCVD films, ${ }^{13}$ and up to $10^{14} \mathrm{~cm}^{-3}$ in some of the thin $(2.5 \mu \mathrm{m})$ HVPE films. ${ }^{8}$ The nature of the broad band-like feature in the ODLTS spectra in Fig. 4 is not quite clear. Those could be the same centers as detected in low temperature $C-V$ and $C-T$ measurements but this question needs further study.

It is natural to ask next whether or not any of the hole traps we see could be associated with threading dislocations in HVPE films. The deep acceptor traps observed in low temperature $C-V$ characteristics after illumination do show some evidence for such a relation if one compares the densities of these traps in the 5 and $68 \mu \mathrm{m}$ samples with the dislocation densities measured by TEM in Ref. 3. For instance, for the $5 \mu \mathrm{m}$ sample the threading dislocation density measured by TEM in Ref. 3 was $2 \times 10^{9} \mathrm{~cm}^{-2}$ and the $N_{\text {deep }}$ value is $2 \times 10^{16} \mathrm{~cm}^{-3}$. For the $68 \mu \mathrm{m}$ sample the dislocation density is $10^{8} \mathrm{~cm}^{-2}$ and the $N_{\text {deep }}$ concentration from Eq. (1) is $2.2 \times 10^{15} \mathrm{~cm}^{-3}$. One more argument in favor of such a correlation is the fact that the acceptors in question appear to form a band of states rather than an isolated level. Theoretical analysis carried out in several papers ${ }^{14-16}$ suggests that acceptor states on edge dislocations are mainly due to the Ga vacancies in the dislocation core or, possibly, to complexes of such vacancies with oxygen. ${ }^{15}$ In that case, the averaged volume density of dislocation related acceptor states could be estimated as the fraction of sites on a given dislocation core capable of trapping vacancies, divided by the lattice parameter along the dislocation line, multiplied by the dislocation density. ${ }^{15}$ The measured overall concentration of our acceptor centers in the 5 and $68 \mu \mathrm{m}$ samples coincides very reasonably with this estimated volume concentration of $\mathrm{Ga}$ vacancies along the dislocation core. Such attribution also agrees very reasonably with the estimates of the $\mathrm{Ga}$ vacancies concentration made on the basis of the positron annihilation experiments performed for the present set of HVPE samples as a function of the samples' thickness. ${ }^{12}$ The results for the thinnest $2.6 \mu \mathrm{m}$ sample are, of course, discouraging in that sense because they break this nice correlation and suggest that the density of traps is sensitive not only to the dislocation density but also to some other factors. However, similar measurements on MOCVD and HVPE samples with dislocation densities over $10^{9} \mathrm{~cm}^{-2}$ gave for such states an overall density of about $2 \times 10^{16} \mathrm{~cm}^{-3}$, in agreement with the general trend presented by Fig. 1 and Table I. ${ }^{8}$ We would also like to mention here that the deep acceptor states found in the $C-V$ and $C-T$ experiments discussed above have earlier been shown to effectively capture both holes (during their charging under illumination) and electrons (during their discharging by the forward bias pulse) and thus are suitable candidates for the role of the major recombination centers.

The $E_{v}+0.9 \mathrm{eV}$ traps also show a general tendency to decrease their concentration with sample thickness (see Fig. 4). However, for high-dislocation-density material (thin HVPE films, MOCVD films) the concentration of such traps varies in so wide a range (see the discussion above in rela- 
tion to Fig. 4), from below the detection limit to well over $10^{15} \mathrm{~cm}^{-3}$ (see Refs. 8 and 12), that the trend we see in Fig. 4 seems to be rather a reflection of the general improvement in crystalline quality of the samples than of the decrease in dislocation density. But more study seems to be in order here.

\section{CONCLUSIONS}

We have shown that deep hole traps located below the Fermi level and having a high density on the order of about $10^{15}$ to $10^{16} \mathrm{~cm}^{-3}$ can be present in HVPE $n$-GaN samples as evidenced by low temperature $C-V$ and $C-T$ measurements before and after illumination. The density of these traps tends to decrease with increased sample thickness (decreased dislocation density) and the results of $C-T$ measurements suggest that these states form a band of states. Both facts make such defects likely candidates for the dislocationrelated levels and since they have been shown to be able to effectively capture both holes and electrons they could prove to be suitable candidates for the role of the major recombination states in the low-angle grain boundaries.

ODLTS measurements also show the presence of other hole traps at levels near $E_{v}+0.9 \mathrm{eV}$ and with concentrations strongly decreasing with increased layer thickness. In general, an increase of layer thickness in the HVPE process seems to significantly improve the situation with regard to the density of deep hole traps. Together with the earlier observations for a general decrease in the density of electron traps $^{3}$ this makes such thick HVPE samples attractive for various electronic applications.

\section{ACKNOWLEDGMENTS}

The work at IRM was supported in part by a grant from the Russian Foundation for Basic Research (Grant No. 0102-17230). The work of Z-Q.F. and D.C.L. was supported under AFOSR Grant No. F49620-00-1-0347.

${ }^{1}$ R. J. Molnar, W. Götz, L. T. Romano, and N. M. Johnson, J. Cryst. Growth 178, 147 (1997).

${ }^{2}$ S. D. Lester, F. A. Ponce, M. G. Craford, and D. A. Steigerwald, Appl. Phys. Lett. 66, 1249 (1995).

${ }^{3}$ Z.-Q. Fang, D. C. Look, J. Jasinski, M. Benamara, Z. Liliental-Weber, and R. J. Molnar, Appl. Phys. Lett. 78, 332 (2001).

${ }^{4}$ D. C. Look and R. J. Molnar, Appl. Phys. Lett. 70, 3377 (1997).

${ }^{5}$ W. Götz, J. Walker, L. T. Romano, N. M. Johnson, and R. J. Molnar, Mater. Res. Soc. Symp. Proc. 449, 525 (1997).

${ }^{6}$ L. Chernyak, A. Osinsky, G. Nootz, A. Schulte, J. Jasinsky, M. Benamara, Z. Liliental-Weber, D. C. Look, and R. J. Molnar, Appl. Phys. Lett. 77, 2695 (2000).

${ }^{7}$ Z. Z. Bandic, P. M. Bridger, E. C. Piquette, and T. C. McGill, Solid-State Electron. 44, 221 (2000).

${ }^{8}$ A. Y. Polyakov, N. B. Smirnov, A. V. Govorkov, M. G. Mil'vidskii, A. S. Usikov, N. M. Shmidt, B. V. Pushnyi, D. V. Tsvetkov, S. I. Stepanov, and V. A. Dmitriev, MRS Internet J. Nitride Semicond. Res. 5S1, W11.81 (2000).

${ }^{9}$ G. M. Martin, A. Mittoneau, D. Pons, A. Mircea, and D. W. Woodard, J. Phys. C 13, 3855 (1980).

${ }^{10}$ A. Y. Polyakov, N. B. Smirnov, A. V. Govorkov, D. W. Greve, M. Skowronski, M. Shin, and J. M. Redwing, MRS Internet J. Nitride Semicond. Res. 3, 37 (1998)

${ }^{11}$ L. S. Berman and A. A. Lebedev, Capacitance Spectroscopy of Deep Centers in Semiconductors (Nauka, Leningrad, 1981) (in Russian).

${ }^{12}$ D. C. Look, C. E. Stutz, R. J. Molnar, K. Saarinen, and Z. Liliental-Weber, Solid State Commun. 117, 571 (2001).

${ }^{13}$ A. Y. Polyakov, N. B. Smirnov, A. S. Usikov, A. V. Govorkov, and B. V. Pushniy, Solid-State Electron. 42, 1959 (1998).

${ }^{14}$ A. F. Wright and U. Grossner, Appl. Phys. Lett. 73, 2751 (1998).

${ }^{15}$ D. C. Look and J. R. Sizelove, Phys. Rev. Lett. 82, 1237 (1999).

${ }^{16}$ J. Elsner, J. Jones, M. I. Heggie, P. K. Stitch, M. Haugk, Th. Frauenheim, S. Oberg, and P. R. Briddon, Phys. Rev. B 58, 12571 (1998). 